

\section{ed on Oral Hygiene"}

'I WANTED A WAY THAT I COULD GIVE

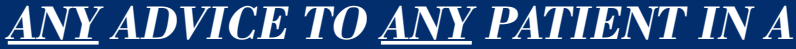

\section{ok to take hom \\ WAY THAT THEY WILL REMEMBER

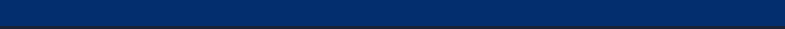 AND ACT UPON'} d oral hygier al tips discus

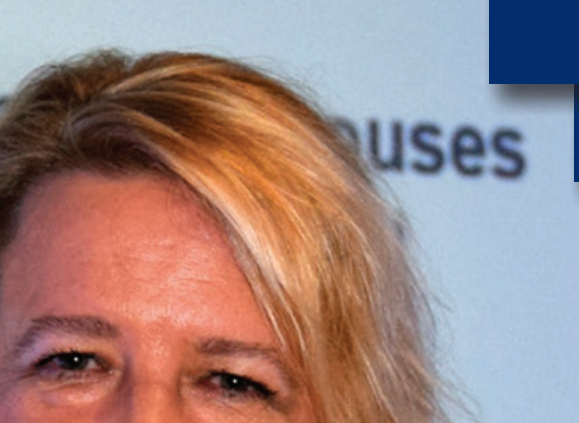

Do you come across people who still hold the misconception that dental hygienists 'just clean teeth'? No, not too much. I have noticed that I now treat more male patients than when I first qualified. This is perhaps due to better oral health awareness or maybe they want to improve their appearance. Either is good

and from that starting point you can try and connect with the patient and get them on board to improving their oral health.

What gave you the idea for the Hooked on Oral Hygiene tool?

I wanted a way that I could give any advice to any patient in a way that they will remember and act upon. We all give tailored advice to our patients in the clinic every day of the week but it can be easy to forget this advice if it is not written down. I needed a simple idea that would help patients remember this advice long after they have left my consultation room. Therefore, it was important to consider the format; a post-it note or a scrap of paper is easily lost at the bottom of a bag, or left in a drawer. So, I thought about how to keep the message on display, and that's how I came up with the idea for the Hooked on Oral Hygiene tool.

It is a hanger style hand-out, similar to a 'Do Not Disturb' sign that you find at hotels. It is printed on steam proof paper so it can survive in any bathroom environment. I think the final design looks great, and it's something that patients should be happy to hang on their bathroom door or cabinet as a visual reminder of the advice they received from their dental professional. On the front of the hand-out there are three boxes where we can write personalised tips and advice for patients, such as brushing twice a day, flossing or chewing sugar-free gum in between meals. There is even space to write the time and date of the patient's next check-up. On the reverse side, there is an illustration of the patient's mouth that can be marked up to show them which areas to focus on more when brushing. I really hope it will encourage patients to 
improve their oral hygiene, and maintain those good habits in between dental check-ups.

How did you go about making your idea into an actual product?

It was a very exciting experience to develop the tool; I worked closely with the Wrigley Oral Healthcare Programme (WOHP) team, the British Society of Dental Hygiene and Therapy (BSDHT), the graphic designer and the whole project team, and to see my idea come to life has been totally amazing.

The development of the tool definitely required a lot of thought and creativity. The wider project team and I met on a regular basis to discuss aspects of the design, the type of paper that should be used, the presentation and various other facets of the tool.

The wider project team and I met regularly to discuss aspects of the design; it was important for the designers to really understand the interaction between dental professionals and our patients in order to help me produce the perfect tool. There were many discussions around the look and feel of the tool, the prescription-pad style design, the design of the mouth, and the best paper to use

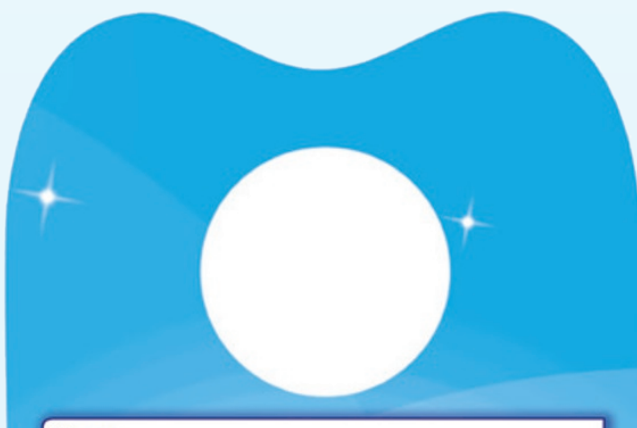

\section{Name:}

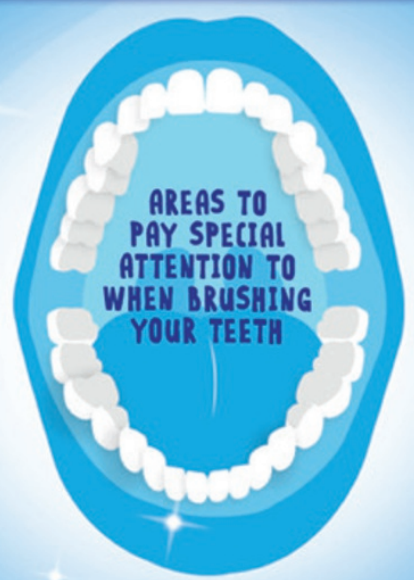

GET HOOKED ON BETTER ORAL CARE - GET HOOKED ON A HEALTHY SMILE

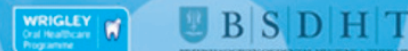

so it wouldn't fall apart in the bathroom. We tested several different types of steam proof paper to make sure we got everything just right.

The tool was officially launched on 20 March 2016, to coincide with World Oral Health Day. As part of the announcement I was honoured to speak at the BSDHT Thames Valley regional group Spring Scientific meeting the day before, allowing me to introduce the tool to other members. A press release was also distributed throughout the UK and the BSDHT shared an email announcement with their network.

\section{How did you hear about the Oral Hygiene By Design Award?}

I first became aware of the award when I saw a large colourful advert in a copy of the BSDHT's journal Dental Health. It said 'Unleash your creative talents and design your ideal oral hygiene tool' and I thought it would be interesting to see what the eventual winning entry would be because I couldn't think of anything initially.

I have been a member of BSDHT since I first qualified as a dental hygienist and really enjoy going to the different scientific meetings

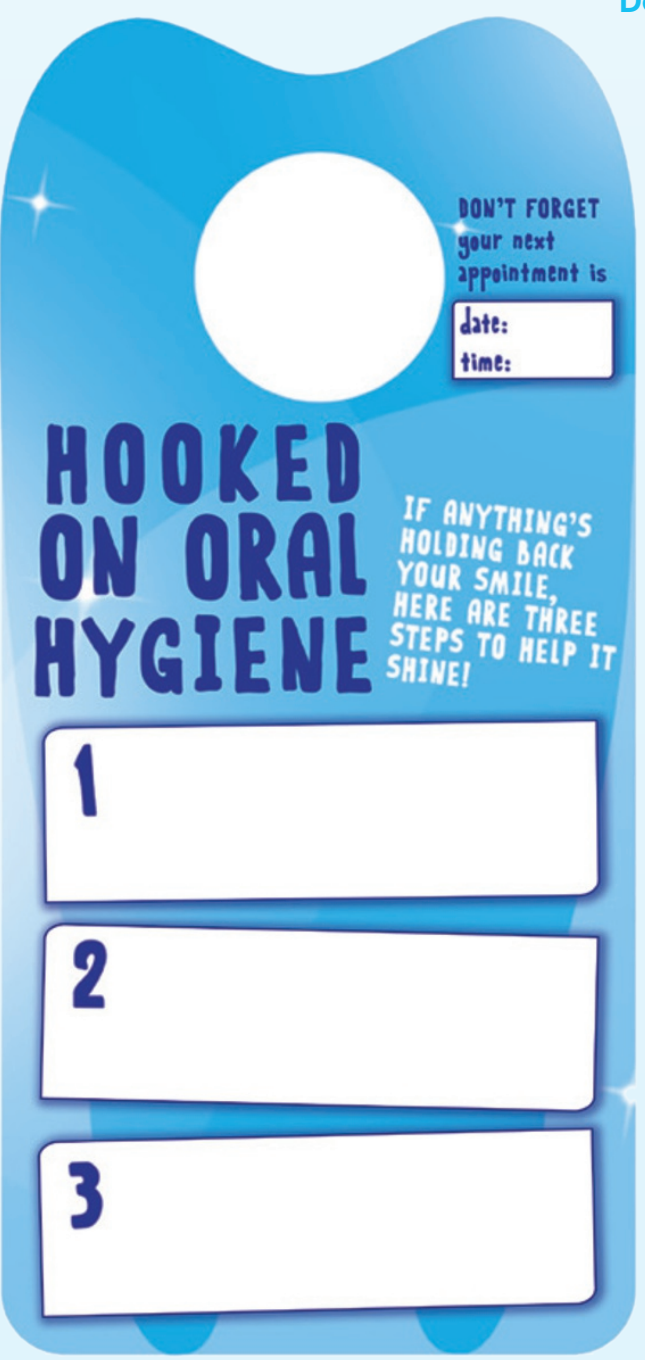

held by the various Regional Groups - the ones that I am able to travel to.

How did it feel to win the award? I was absolutely delighted and still am!

\section{Do you know roughly how many patients are now using the Hooked tool?}

Since the tool launched in March, WOHP has been inundated with requests and I have personally handed out 6,000 tools to dental hygienists and therapists at various BSDHT events. I have also been able to share the tool with work colleagues, patients and friends and family. It's been very rewarding to see patients taking the Hooked on Oral Hygiene tool away with them after their visits to clinic. So far my patients have responded very well to the tool and have been keen to take them back home with them and I would encourage other practitioners to give the tools a try with patients in their clinics as well. If anyone wants to order the tool to use with their patients, they can request them for free via the WOHP website www. wrigleyoralhealthcare.co.uk/.

Do you have any plans to create other tools or products (they may be secret!)?

Maybe. Before I came up with my idea I did toy with a few other concepts, but I rejected these for different reasons - but I could think about it again ... I hadn't really considered it before now.

\section{What are you future career plans?}

Winning the award has created a number of opportunities. I am going to my first ever international conference next June in Switzerland, where the tool will be available to delegates, and then I am going to the BSDHT Oral Health Conference in Belfast in November. I'm interested to see what other international events will be held and what I might learn from them.

\section{Are you passionate about teeth and being a dental hygienist?}

Yes it's a passion you have to have. It's a caring profession and to be fully committed to caring you have to be passionate about it. 